OPEN

SUBJECT AREAS:

ALLERGY

AUTOIMMUNITY

EXPERIMENTAL MODELS OF

DISEASE

Received

10 March 2014

Accepted

1 July 2014

Published

11 August 2014

Correspondence and requests for materials should be addressed to

S.F. (susetta.finotto@ uk-erlangen.de)

* These authors contributed equally to this work.

\section{Role of Tyk-2 in Th9 and Th17 cells in allergic asthma}

\author{
Caroline Übel ${ }^{1 *}$, Anna Graser ${ }^{1 *}$, Sonja Koch' ${ }^{1}$ Ralf J. Rieker ${ }^{2}$, Hans A. Lehr ${ }^{3}$, Mathias Müller ${ }^{4}$ \\ \& Susetta Finotto'
}

'Laboratory of Cellular and Molecular Immunology of the Lung, Institute of Molecular Pneumology, University of Erlangen-Nürnberg, 91054 Erlangen, Germany, ${ }^{2}$ Institute of Pathology, University of Erlangen-Nürnberg, 91054 Erlangen, Germany, ${ }^{3}$ Institute of Pathology, Centre Hospitalier Universitaire Vaudois, 1011 Lausanne, Switzerland, ${ }^{4}$ Institute for Animal Breeding and Genetics, University of Veterinary Medicine Vienna, 1210 Vienna, Austria.

In a murine model of allergic asthma, we found that Tyk-2 $2^{(--)}$asthmatic mice have induced peribronchial collagen deposition, mucosal type mast cells in the lung, IRF4 and hyperproliferative lung Th2 $\mathrm{CD}_{4}^{+}$ effector T cells over-expressing IL-3, IL-4, IL-5, IL-10 and IL-13. We also observed increased Th9 cells expressing IL-9 and IL-10 as well as Thelper cells expressing IL-6, IL-10 and IL-21 with a defect in IL-17A and IL-17F production. This Thelper phenotype was accompanied by increased SOCS3 in the lung of Tyk-2 deficient asthmatic mice. Finally, in vivo treatment with rIL-17A inhibited local CD4 ${ }^{+} \mathrm{CD} 25^{+} \mathrm{Foxp}^{+} \mathrm{T}$ regulatory cells as well as Th2 cytokines without affecting IL-9 in the lung. These results suggest a role of Tyk-2 in different subsets of Thelper cells mediated by SOCS3 regulation that is relevant for the treatment of asthma, cancer and autoimmune diseases.

$\mathrm{n}$ mammals cytokines signal primarily through signaling pathways involving cytokine-receptor-activated Janus kinases (JAKs 1-3 and Tyrosine kinase 2) and STAT (Signal and Activators of Transcription 1-6) transcription factors ${ }^{1}$. Tyk- 2 has been first described by Velazquez et al. ${ }^{2}$ and it is known to be involved in interleukins IL-6, IL-10, IL-11, IL-12, IL-13, IL-22, IL-23, IL-27, IL-31 and IFN (interferon) $\alpha, \beta$ and $\lambda$ signal transduction ${ }^{3,4}$. However, IL-6 and IL-10 mediated signal transduction is still functional in Tyk-2 $2^{(-1-)}$ mice . $^{5,6}$. Tyk-2 deficiency in humans has been found to be associated with an increased susceptibility to viral and mycobacterial infections as well as atopic dermatitis, hypereosinophilia and Hyper IgE syndrome ${ }^{7}$. These symptoms hint towards a Th2-skewed cytokine profile in the absence of Tyk-2 function. As these cytokines play a major role in the pathogenesis of allergic diseases such as asthma, we analyzed Tyk- $2^{(-1-)}$ mice in a murine model of allergic asthma ${ }^{8}$.

Allergic asthma is an inflammatory disease of the airways which occurs with increased prevalence during the last decades especially in the developed world ${ }^{9,10}$. However, the molecular mechanism of this disease needs further investigations. Recently, the role of IL-17A and IL-9 in an experimental model of asthma has been further explored. IL-9 was first characterized as a T cell and mast cell growth factor ${ }^{11}$. Transgenic expression of IL-9 in the lung results in allergic inflammation dependent on Th2 cytokines ${ }^{12}$. Moreover, blockade of IL-9 inhibits mastocytosis and airway remodeling ${ }^{13}$. Th9 cells are induced by TGF- $\beta$ and IL- ${ }^{14}$.

IL-17A was found to play a pathogenetic role during the developmental phase of the disease, while it ameliorates established allergic disease ${ }^{15}$. Since IL-17A is a known neutrophil attracting cytokine, it has been hypothesized that it is more associated with neutrophil-dominated allergic asthma ${ }^{16,17}$. This form of the disease is known to be more severe and difficult to treat than eosinophil-dominated asthma. Additionally, IL-17A has also been identified to be a main causative agent for the occurrence of airway hyperreactivity, one of the key hallmarks of allergic asthma ${ }^{16,18,19}$. The suppressor of cytokine signalling (SOCS)-3 activation, inhibits several cytokine signaling in Thelper cells as well as in dendritic cells thus regulating and having a significant impact on the development of the downstream immune responses ${ }^{20}$.

Here, we show that Tyk-2 $2^{(-)}$mice have hypereosinophilia and hyper IgE associated with increased remodeling, mast cells, effector Th2 and Th9 cells in the airways. This phenotype was found to be associated with a defect in Th17 cell polarization. Moreover, in the lung of asthmatic Tyk-2 deficient mice, protein level was found upregulated. Treatment with rIL-17A led to a down-regulation of Th2 and T regulatory cells in the lung of Tyk-2 $2^{(-l-)}$ mice. In conclusion, Tyk-2 plays a fundamental role downstream of many cytokine receptors in controlling allergic asthma by limiting different subsets of T helper cell derived cytokines such as IL-6, IL-9 and IL-21 and 
a
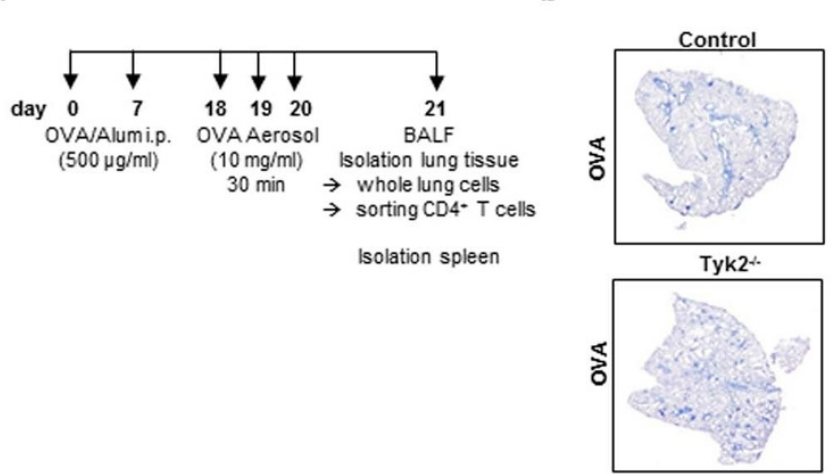

C

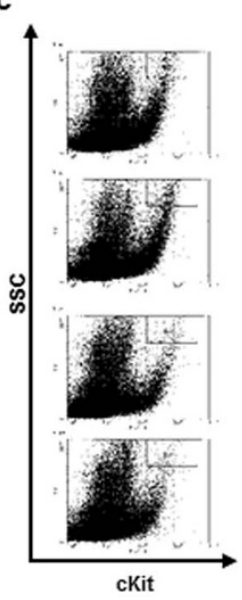

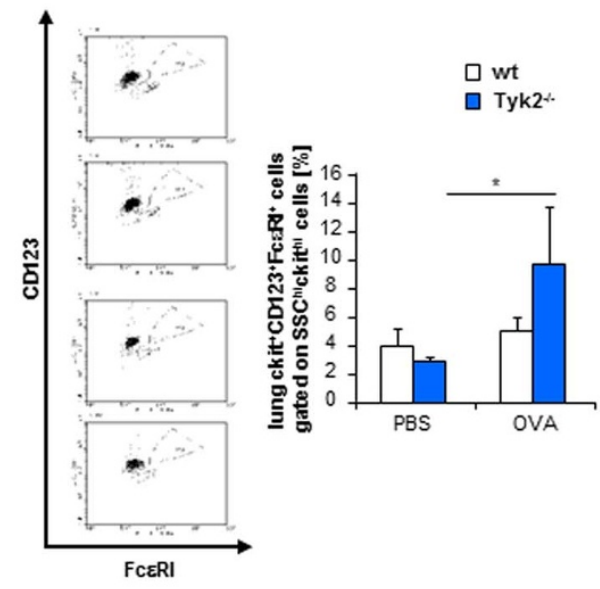

f

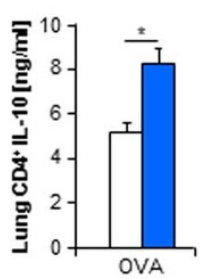

g

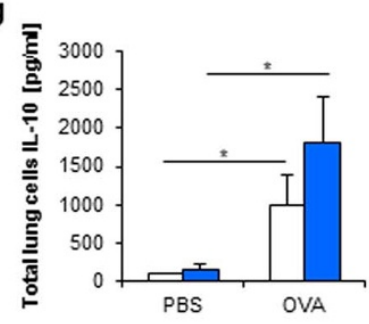

h

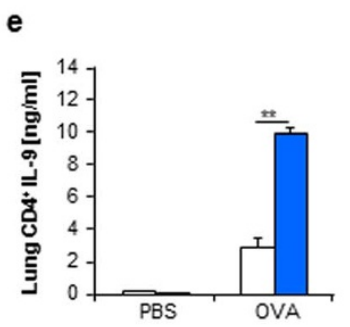

i
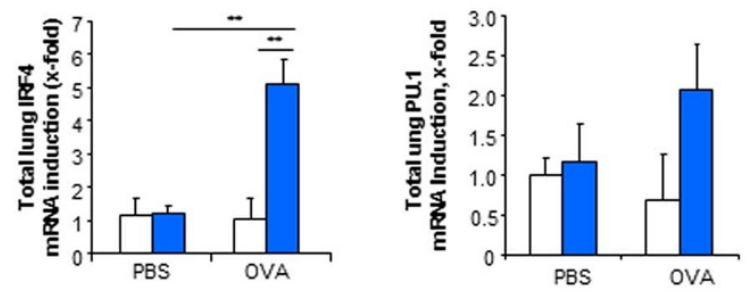

Figure 1 Tyk-2 deficiency induced mast cell differentiation and IL-9 in the lung of asthmatic mice. (a). experimental design (b). Lung histology for mast cell detection with Toluidine Blue staining. (c). Total lung cells from naïve and OVA treated mice were incubated with antibodies against CD117 (c-kit), CD123 (IL-3R $\alpha$ ) and FceRI and analyzed by flow cytometry $(\mathrm{n}=2-4 ; \mathrm{p}=0.05)$. (d).-(f). Lung CD4 ${ }^{+} \mathrm{T}$ cells from naïve (PBS) and OVA treated mice were isolated and incubated for $24 \mathrm{~h}$ with $\alpha$-CD3 and $\alpha$-CD28 antibodies. The supernatants were analyzed by ELISA for IL-3 (d), IL-9 (e) and IL-10 (f) $((\mathrm{d}): \mathrm{n}=4 ; \mathrm{p}=0.002 ; \mathrm{p}=0.004 ;(\mathrm{e}): \mathrm{n}=3-4 ; \mathrm{p}=0.037 ; \mathrm{p}=0.015 ; \mathrm{p}=0.024 ;(\mathrm{f}): \mathrm{n}=3 ; \mathrm{p}=0.012$, respectively) (g). Release of IL-10 by total lung cells $((\mathrm{g}): \mathrm{n}=3 ; \mathrm{p}=0,049 ; \mathrm{p}=0,02)(\mathrm{h})$. and (i). Irf4 and Pu.1 mRNA expression in total lung $((\mathrm{h}): \mathrm{n}=2-4 ; \mathrm{p}=0,001 \mathrm{p}=0,007 ;(\mathrm{i}): \mathrm{n}=3-4)$.

inducing IL-17A and IL-17F. Tyk-2 in asthma probably regulates these cytokines in the presence of suppressed levels of SOCS3.

\section{Results}

Tyk2 deficiency leads to a severe Th2 allergic phenotype after allergen challenge. Allergic asthma induced in Tyk2 deficient mice, leads to severe infiltration of eosinophils in the BALF as compared to the wild type littermates mice (Fig. S1a-c). This effect is probably mediated by the increase of IL-5, the eosinophil growth and differentiating factor (Fig. S1 d). Tyk2 deficiency is also known to be associated with hyper IgE production ${ }^{7}$ (Fig. S1e). Along with hyper-IgE these mice also displayed elevated levels of $\operatorname{IgG}_{2 \mathrm{~A}}$ compared to wild type mice (Fig. S1f). In spite of elevated Th2 cytokines and inflammation in the airways, Tyk- 2 deficient mice did not show increased airway hyperresponsiveness to methacholine after allergen sensitization and challenge (Fig. S1g).

We also detected induced fibrosis in the lung of Tyk $2^{(-1-)}$ mice after allergen sensitization and challenge (Fig. S1h). Consistent with these findings, lung $\mathrm{CD}^{+}{ }^{+} \mathrm{T}$ cells isolated from the Tyk- 2 deficient mice released increased amounts of IL-13, a Th2 cytokine which favors fibrosis, as compared to wild type littermates (Fig. S 1i).
Increased Th9 and mast cell number in the lung of Tyk-2 $2^{(-/-)}$mice. Mast cells are major players in the induction of allergic diseases such as asthma. Since it has been previously described that Tyk- $2^{(-l-)}$ mice show an increased Th2 differentiation and thus a more severe asthmatic phenotype ${ }^{21}$, we analyzed the number of mast cells in Tyk-2 $2^{(-1-)}$ mice after allergen treatment. In a murine model of allergic asthma (Fig. 1a), we thus analyzed the lung section stained with Toluidine Blue, a specific staining for mast cells, and found an increased number of positive cells in the absence of Tyk-2 (Fig. 1b). We then analyzed total lung cells by flow cytometry. Mast cells were defined as c-kit ${ }^{\text {hi }} \mathrm{CD} 123^{+} \mathrm{Fc} \varepsilon \mathrm{RI}^{+}$cells gated on SSC ${ }^{\mathrm{hi}} \mathrm{c}-\mathrm{kit}^{\mathrm{hi}}$. These mast cells are known as mucosal mast cells as they express the IL$3 \mathrm{R}\left(\mathrm{CD} 123^{+}\right)$. The analysis showed a significant up-regulation of mast cells in Tyk-2 $2^{(-)}$mice after allergen challenge (Fig. 1c) identifying mucosal mast cell number as a possible explanation for the allergic phenotype of these mice.

Finally, we looked at the concentrations of the two main mast cellinducing cytokines, IL-3 and IL-9. Further analysis showed that lung $\mathrm{CD} 4{ }^{+} \mathrm{T}$ cells from Tyk-2 $2^{(-/)}$mice released significantly more IL-3 (Fig. 1d) and IL-9 (Fig. 1e) as well as IL-10 (Fig. 1f and 1g) after ovalbumin challenge. Analysis of the recently found Th9-defining transcription factor interferon-regulatory factor 4 (Irf4), which also 
a
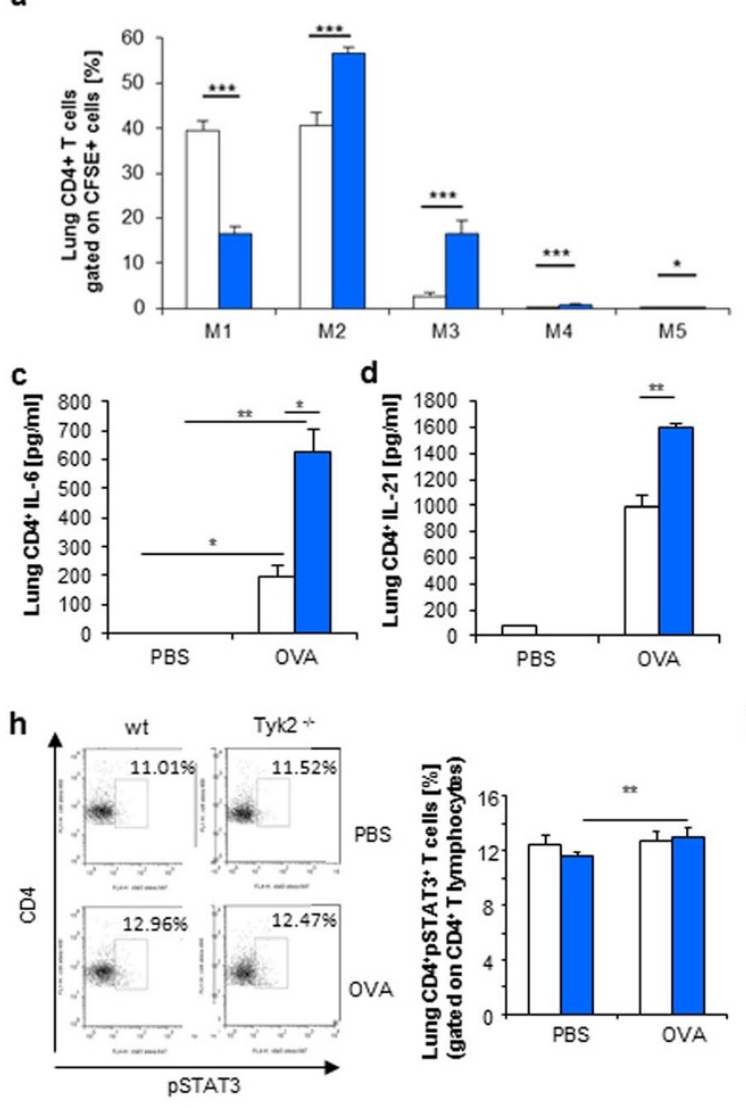

b
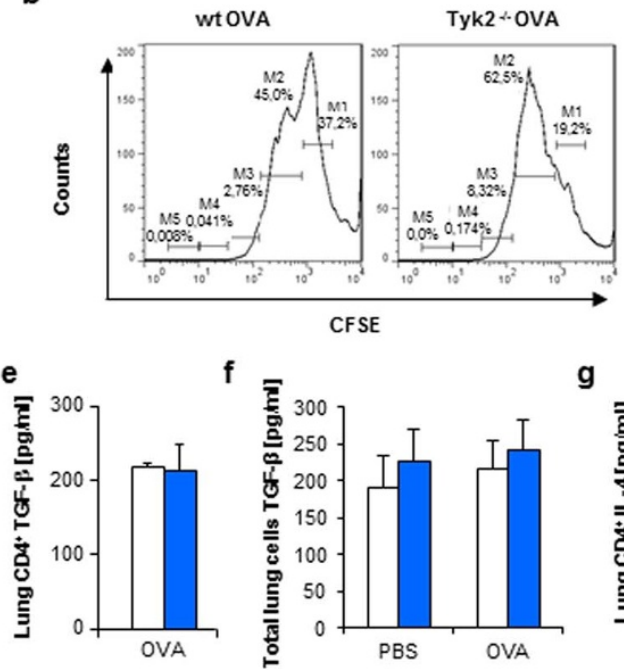

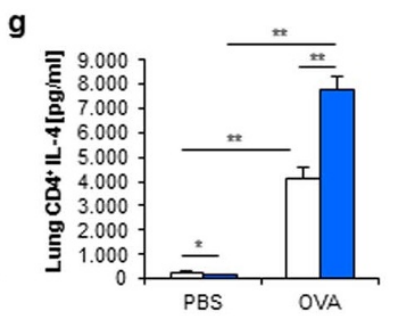

i
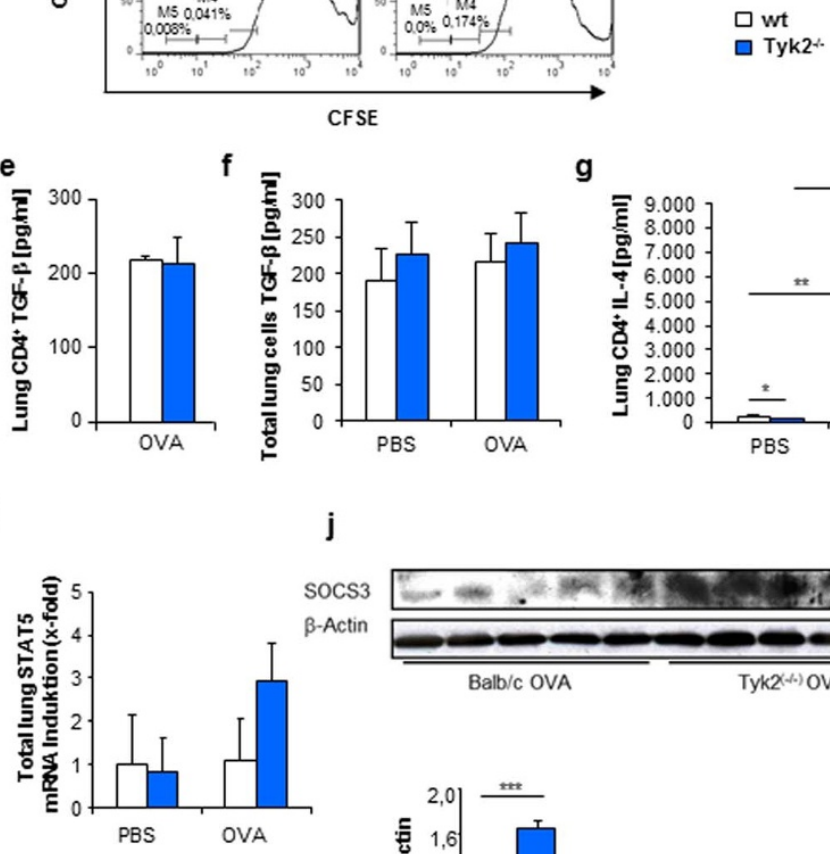
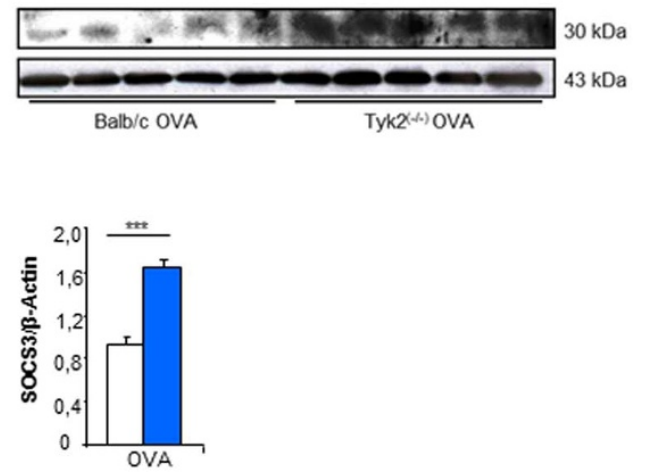

Figure $2 \mid$ Tyk-2 inhibited T cell proliferation in asthma. (a). and (b). CFSE labelled spleen CD4 ${ }^{+} \mathrm{T}$ cells from naïve and asthmatic Tyk-2 ${ }^{(-1-)}$ mice were analyzed for their proliferation $(\mathrm{n}=4-5 ; \mathrm{M}=$ Mitosis: $\mathrm{M} 1 \mathrm{p}=0,0000, \mathrm{M} 2: \mathrm{p}=0,0000, \mathrm{M} 3: \mathrm{p}=0,0001, \mathrm{M} 4: \mathrm{p}=0,0005, \mathrm{M} 5: \mathrm{p}=0,0459)$. (c-e). CD4 ${ }^{+} \mathrm{T}$ cells were isolated from the lungs of naïve and OVA-treated wild type and Tyk- $2^{(-1-)}$ mice and cultured for $24 \mathrm{~h}$ with $\alpha$-CD3 and $\alpha$-CD28 antibodies and supernatants were analyzed by ELISA for IL-6 ((c): $\mathrm{n}=2-3 ; \mathrm{p}=0.0014, \mathrm{p}=0,0053, \mathrm{p}=0,0052), \mathrm{IL}-21((\mathrm{~d}): \mathrm{n}=2-3 ; \mathrm{p}=0.0015)$, TGF- $\beta((\mathrm{e}): \mathrm{n}=3))$. (f). TGF- $\beta$ levels in the supernatants of total lung cells $(\mathrm{n}=3) .(\mathrm{g}) . \mathrm{CD} 4^{+}$T cells were isolated from the lungs of naïve and OVA-treated wild type and Tyk$2^{(-1-)}$ mice and cultured for $24 \mathrm{~h}$ with $\alpha$-CD3 and $\alpha$-CD28 antibodies and supernatants were analyzed by ELISA for IL-4 (n $=2-4 ; \mathrm{p}=0,019 \mathrm{p}=0,005$ $\mathrm{p}=0,001 \mathrm{p}=0,0046)$. (h). Total lung cells from wild type and Tyk-2 ${ }^{-/-}$mice were incubated with antibodies against CD4 and pSTAT3 ( $\mathrm{n}=4-5$; $\mathrm{p}=0.002)$ and analyzed by flow cytometry. (i). Total lung RNA was analyzed after $\mathrm{cDNA}$ synthesis by qPCR for the expression of Stat5 mRNA $(\mathrm{n}=3)$. ( $\mathrm{j})$. Western blot analysis was performed on total lung protein extracts from OVA-treated mice. The membrane was probed with antibodies against SOCS3 and $\beta$-Actin as normalization control $(\mathrm{n}=5 ; \mathrm{p}=0.00003)$.

regulates Th2 and Th17 cell differentiation ${ }^{22,23}$ also revealed induced expression levels after allergen challenge in Tyk-2 $2^{(-1-)}$ mice compared to wild-type mice in total lung (Fig. 1h). Finally, the most recognized Th9 transcription factor $P u .1^{24}$ was also found upregulated at the mRNA level in the lung of Tyk- 2 deficient mice (Fig. 1i). These data show an increased number of mast cells and mast cell growth factors such as IL-3 and IL-9 in the lung of Tyk-2 $2^{(-1-)}$ mice.

Increased proliferation of lung $\mathrm{CD}^{+} \mathrm{T}$ cells isolated from Tyk$2^{(-/-)}$asthmatic mice. To investigate the role of Tyk- 2 in T cells in a setting of allergic asthma, we sorted out lung $\mathrm{CD}^{+} \mathrm{T}$ cells from asthmatic mice and analyzed their proliferation after CFSE staining in a four days cell culture. As shown (Fig. 2 a and b), $\mathrm{CD} 4^{+} \mathrm{T}$ cells isolated from the lung of Tyk-2(-1-) mice proliferated more than those from the lung of wild type littermates, indicating increased effector $\mathrm{T}$ cells in the absence of Tyk-2. We then analyzed IL-6, a T regulatory cell inhibiting cytokine ${ }^{25}$, and found it elevated in the supernatants of cultured lung $\mathrm{CD}^{+} \mathrm{T}$ cells in the absence of Tyk2 in experimental allergic asthma (Fig. 2c). Similarly, IL-21, a cytokine known to counteract $\mathrm{T}$ regulatory cells ${ }^{26}$, was found increased in the supernatants of lung $\mathrm{CD}^{+} \mathrm{T}$ cells of Tyk-2(-l-) mice (Fig. $2 \mathrm{~d}$ ), while TGF- $\beta$, a T regulatory inducing cytokine was found unchanged before and after allergen challenge (Fig. 2e,f). The Th9 subset differentiates in vitro by the addition of TGF-beta and IL- $4^{27}$. We next analyzed IL- 4 which, consistent with a role of Tyk-2 in Th2 cells, was found significantly up-regulated in the supernatants of lung $\mathrm{CD}^{+}$cells isolated from the Tyk-2 $2^{(-1-)}$ mice as compared to those isolated from wild type littermates (Fig. $2 \mathrm{~g}$ ). Taken together, these data support a central role of Tyk-2 in inhibiting Th9 differentiation and in general its $\mathrm{T}$ cell anti-proliferative function in allergic asthma.

Increased SOCS3 in the lung of Tyk-2 ${ }^{(-/-)}$mice in a murine model of allergic asthma. IL- 9 was originally identified as a T cell growth factor and it is a member of the common- $\gamma$-chain-receptor cytokine family including IL-2, IL-4, IL-7, IL-15 and IL-21. The activation of IL- 9 receptor $\alpha$ - $\gamma$-chain induces activation of JAK/1-3 and downstream STAT $1 / 3$ and STAT $5^{28}$. It has been demonstrated that IL-9 induces SOCS3 which then limits IL-9 signaling ${ }^{29}$. Considering that IL-6, IL-21, IL-4 and IL-9 were found elevated in asthma 
a

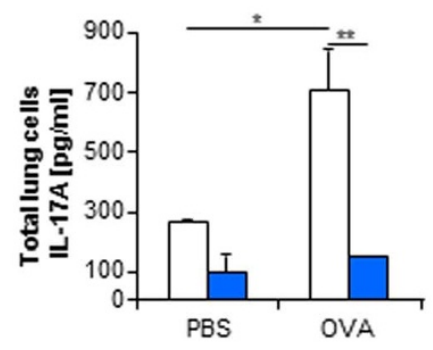

b

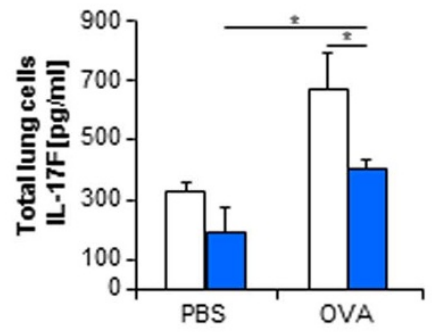

$\square$ wt

$\square$ Tyk2

C
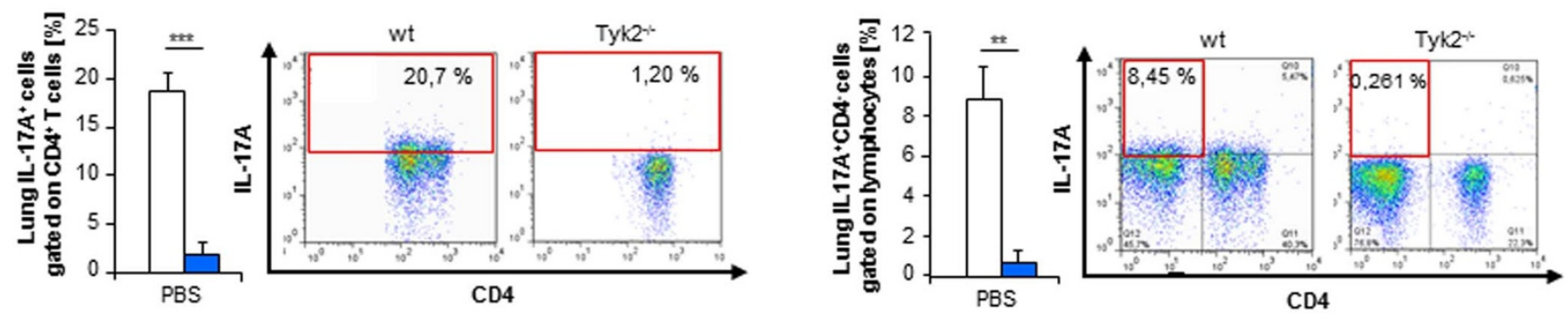

d

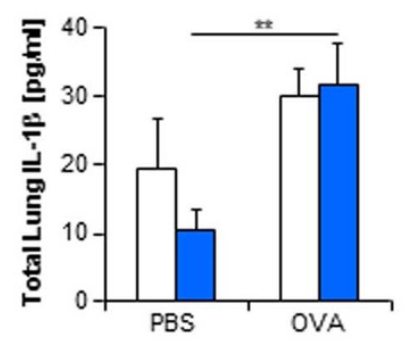

e

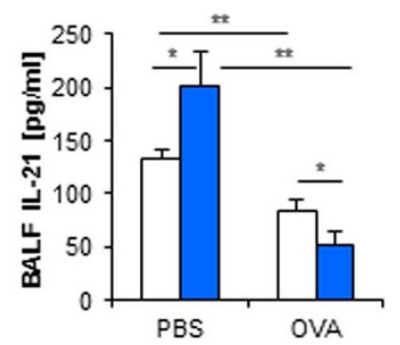

f

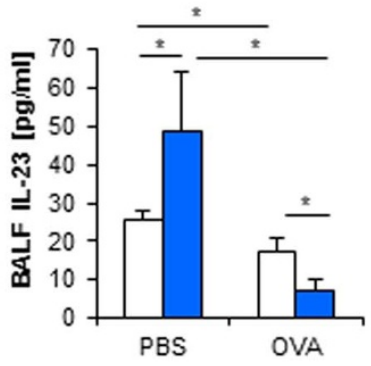

Figure $3 \mid$ Tyk-2 $2^{(-/-)}$mice showed a defective Th17 cytokine production in vivo. (a). and (b). Mice were treated with OVA as described in the

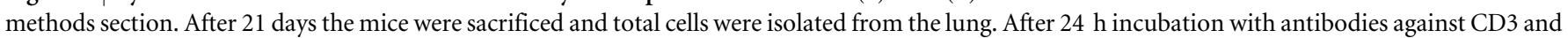

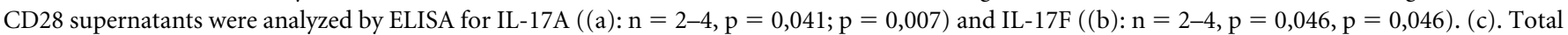

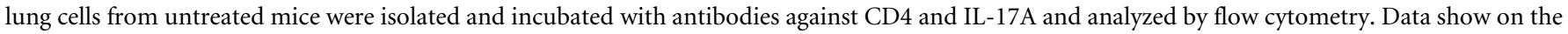

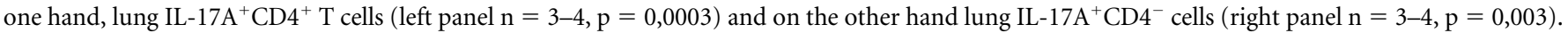

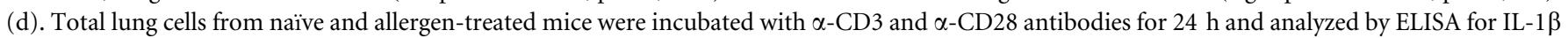

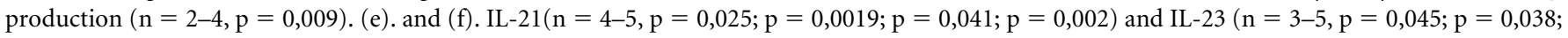
$\mathrm{p}=0,043 ; \mathrm{p}=0,012)$ levels were measured in the BALF of naïve and asthmatic mice.

particularly in the absence of Tyk-2, we then looked at the downstream signal of these cytokines. First, we looked at pSTAT3 which is activated by IL-9 and IL-6. Although it was found elevated in the lung of Tyk-2 $2^{(-1-)}$ asthmatic mice, no difference was observed between wild type and Tyk-2 deficient mice (Fig. 2h). STAT5 mRNA was also not found significantly regulated by Tyk- 2 in this disease model (Fig. 2i). By contrast, SOCS3 protein was found significantly up-regulated in the lung of asthmatic Tyk-2 $2^{(-/-)}$mice (Fig. 2j). Altogether, these data underline a role of IL- 9 mediated by SOCS3 in the lung of Tyk-2 deficient mice.

Tyk-2 deficiency is associated with reduced IL-17A and IL-17F production after allergen challenge. We next analyzed IL-17A and IL-17F levels which we found to be down-regulated in Tyk$2^{(-1-)}$ mice after allergen challenge (Fig. $3 \mathrm{a}, \mathrm{b}$ ) as well as in naive mice (Fig. 3c) compared to wild-type mice.

Next, we looked at the production of the cytokines relevant for Th17 development. IL-1 $\beta$ production was analyzed in total lung cells.
We could observe a significant increase of this cytokine after allergen challenge in Tyk-2 $2^{(--)}$mice (Fig. 3d). Furthermore, in the BALF of naïve Tyk-2 $2^{(-1-)}$ mice we could detect higher amounts of IL-21 (Fig. 3e) and IL-23 (Fig. 3f) than in naive wild-type mice. After allergen challenge, IL-21 and IL-23 were found down-regulated especially in the BALF of Tyk-2 $2^{(-)-}$asthmatic mice. These data on IL-21 are similar to the findings on IL-10. In fact, IL-21 was found upregulated in the supernatants of lung $\mathrm{CD}^{+} \mathrm{T}$ cells after allergen challenge but down-regulated in the BALF. This might be due to IL-21 release by different cell types.

Th17 differentiation is impaired in Tyk-2 $2^{(-/-)}$mice. Tyk-2 is located downstream of IL- 6 and IL-23 signaling that are crucially involved in the generation and proliferation of Th17 cells ${ }^{4,30,31}$. We thus wanted to determine whether alternative pathways were involved in the development of Th17 cells in the absence of Tyk-2. To this aim we isolated splenic $\mathrm{CD}^{+}{ }^{+} \mathrm{CD} 62 \mathrm{~L}^{+} \mathrm{T}$ cells and exposed them to Th17 skewing cell culture conditions $(\alpha-C D 3, \alpha-C D 28$, 
a

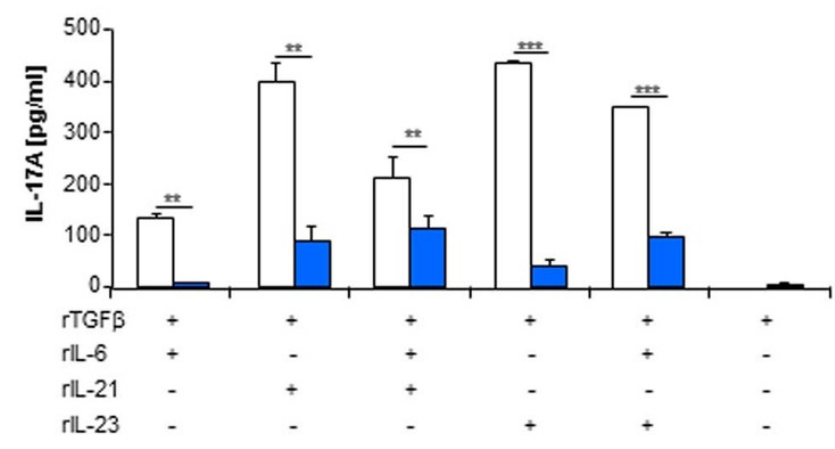

C

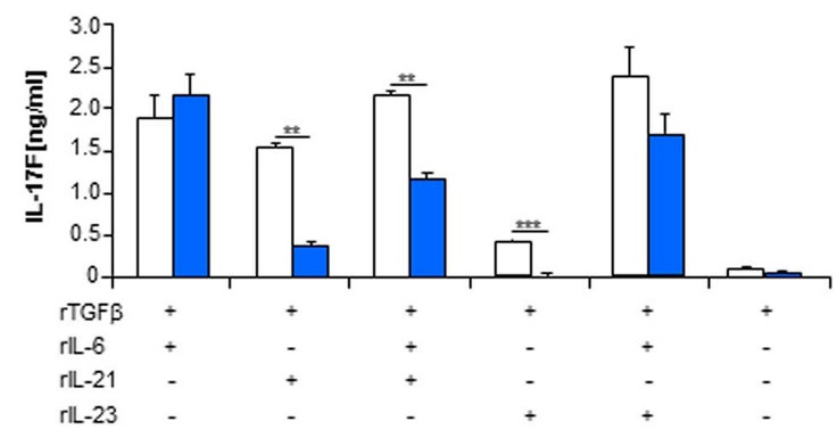

b

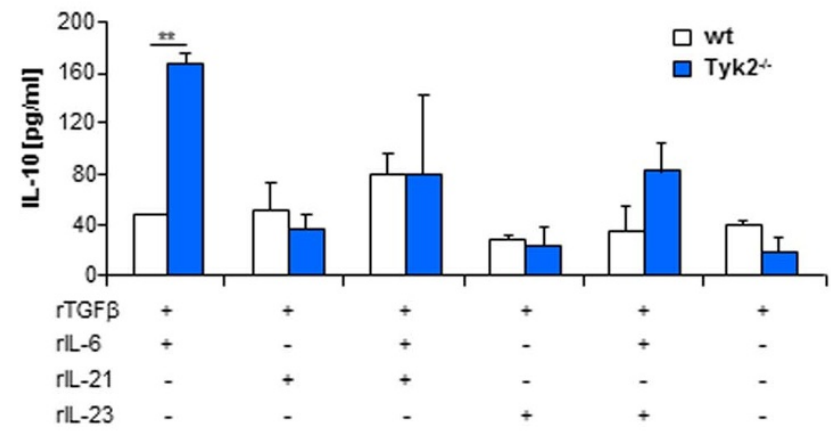

Figure $4 \mid$ Tyk-2 $^{(-/-)}$naïve $\mathrm{CD}^{+} \mathrm{T}$ cells showed a defective Th17 cytokine production ex vivo. Spleen $\mathrm{CD}^{+} \mathrm{CD} 62 \mathrm{~L}^{+} \mathrm{T}$ cells were isolated from naïve Tyk- $2^{(-/-)}$and wild-type mice and treated with antibodies against CD3 $(2 \mu \mathrm{g} / \mathrm{ml}), \mathrm{CD} 28(2 \mu \mathrm{g} / \mathrm{ml}), \mathrm{IL}-4(10 \mu \mathrm{g} / \mathrm{ml})$ and IFN $\gamma(10 \mu \mathrm{g} / \mathrm{ml}) \mathrm{while}$ recombinant cytokines TGF- $\beta$ ( $3 \mathrm{ng} / \mathrm{ml})$, IL-6 $(20 \mathrm{ng} / \mathrm{ml})$, IL-23 $(50 \mathrm{ng} / \mathrm{ml})$ and IL-21 $(80 \mathrm{ng} / \mathrm{ml})$ were added as indicated. After five days the supernatant was collected and analyzed by ELISA for IL-17A $((a): n=2, p=0,004, p=0,009, p=0,0008, p=0,0003, p=0,006)$ IL-10 ((b): $n=2$, $\mathrm{p}=0,003)$ and IL-17F $((\mathrm{c}): \mathrm{n}=2, \mathrm{p}=0,001, \mathrm{p}=0,004, \mathrm{p}=0,0003)$.

$\alpha$-IL-4, $\alpha$-IFN $\gamma$ antibodies) in the presence of either IL- 6 or either IL21 or IL-23 and TGF- $\beta$ (Fig. 4a). Under all these experimental conditions IL-17A production was found significantly reduced in naive $\mathrm{CD}^{+} \mathrm{T}$ cells isolated from $\mathrm{Tyk}-2^{(-l-)}$ mice as compared to cells isolated from the wild type littermates regardless of the cytokine milieu.

IL-10 was found significantly elevated in the Tyk-2 $2^{(-/-)}$cells treated with rTGF- $\beta$ and rIL-6 (Fig. $4 \mathrm{~b}$ ).

By contrast, IL-17F was found to be significantly reduced in Tyk$2^{(-/-)}$cells treated with rTGF- $\beta$ plus either rIL-21 or rIL- 6 and rIL-2 1 or rIL-23 (Fig. 4c).

These data are consistent with a recently described IL-17A inhibitory function of $\mathrm{SOCS}^{32}$.

Treatment of Tyk-2 $2^{(-/-)}$mice with recombinant IL-17A in a murine model of asthma reduced $\mathrm{T}$ regulatory cells. To analyze the role of IL-17A deficiency in the absence of Tyk-2, we thought to treat Tyk-2 deficient mice intranasally with recombinant murine IL$17 \mathrm{~A}$ in a murine model of allergic asthma.

Intranasal application of rIL-17A (Fig. 5a) led to a down regulation of the Th2 cytokines IL-4, IL-5 and IL-13 only in Tyk-2 $2^{(-1-)}$ mice (Fig. 5b-d, respectively). IL-17A is important for the recruitment of neutrophils to the lung during allergic airway disease ${ }^{33}$. We thus analyzed the number of neutrophils in BAL cells of naïve mice and after allergen challenge. We detected a defect of neutrophils in the lung of Tyk-2 $2^{(-1-)}$ mice after allergen challenge. In vivo intranasal application of recombinant IL-17A induced neutrophils in wild type and less inTyk-2(-1-) mice (Fig. 5e). The latter result is consistent with a role of IL-17A on neutrophilia and with defective IL-17A in the lung of Tyk-2 deficient mice. Application of IL-17A and OVA led to a down-regulation of T regulatory cells in Tyk- $2^{(-1-)}$ mice, whereas the number of these cells remained unchanged in wild-type mice (Fig. 5f). Thus, Tyk-2 $2^{(-/-)}$mice had fewer regulatory $\mathrm{T}$ cells after IL-17A treatment than wild type mice consistent with a role of Tyk- 2 in the generation of $\mathrm{T}$ regulatory cells downstream of the IL-17A receptor.

When we analyzed the samples for IL-9 expression. We could detect similar IL-9 levels in lung CD4 ${ }^{+} \mathrm{T}$ cells (Fig. 5g) irrespective of the treatment with rIL-17A. Taken together, these data demonstrate that the exogenous IL-17A can induce neutrophilia in the lung in the presence or absence of Tyk-2 and inhibit T regulatory cells in the absence of Tyk- 2 .

\section{Discussion}

Here, we report a crucial protective regulatory role of Tyk- 2 in allergic asthma. In this study, we analyzed the role of Tyk- 2 on IL9 production and on Th17 polarization in Tyk-2 $2^{(-/-)}$mice compared to wild type mice. Tyk-2 $2^{(-l-)}$ mice produced more IL-9 and Irf4 and less of the Th17-hallmark cytokine IL-17A in vitro. We confirmed these observations in vivo in a murine model of allergic asthma, after allergen challenge. To analyze this finding more closely, we looked at the expression of signaling molecules relevant for IL-9 and IL-17A production. The Th17-inducing and T regulatory cell inhibiting cytokines IL-6 and IL-21 were found up-regulated in the absence of Tyk-2 in the supernatants of lung $\mathrm{CD}^{+} \mathrm{T}$ cells. The expression of SOCS3 is tightly regulated at the protein level. SOCS3 transcription is rapidly induced by a range of type I and type II cytokines, signaling via STAT1 and/or STAT3. The best characterized inducers are members of the gp130 family, including IL-6, IL-11 and LIF. Here, we describe for the first time 
a

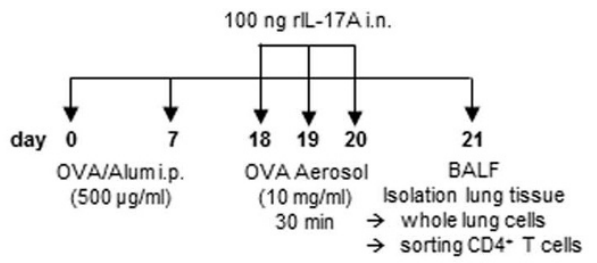

$\square$ wt 口 Tyk2 b

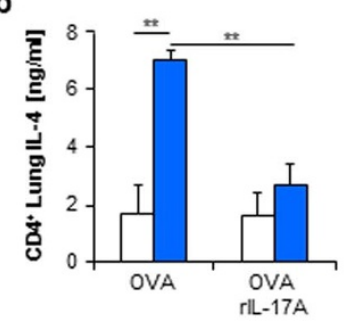

c

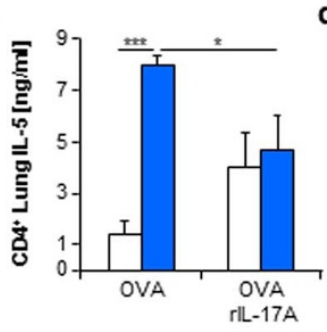

d

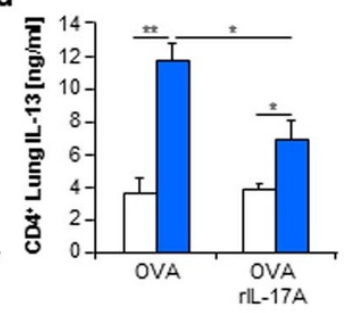

e
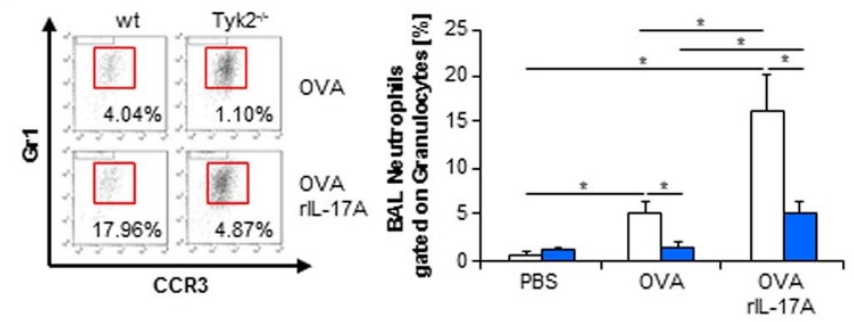

f

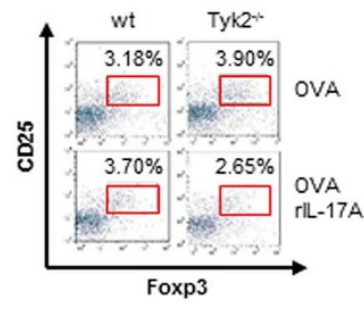

g

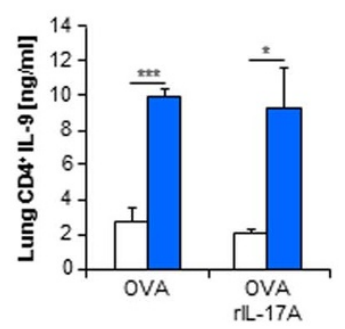

Figure 5 Treatment with rIL-17A led to down-regulation of T regulatory cells in Tyk-2 deficient mice. (a). Mice were treated with OVA alone and OVA + rIL-17A as shown in the experimental design. (b).-(d). Lung CD4 ${ }^{+} \mathrm{T}$ cells from OVA alone and OVA + rIL-17A treated mice were isolated and incubated for $24 \mathrm{~h}$ with $\alpha$-CD3 and $\alpha$-CD28. The supernatants were analyzed by ELISA for IL-4, IL-5 and IL-13 ((b):IL-4: $\mathrm{n}=3-4 ; \mathrm{p}=0.004 ; \mathrm{p}=0.003$; (c): IL-5: $\mathrm{n}=3-4 ; \mathrm{p}=0.0002 ; \mathrm{p}=0.040 ;(\mathrm{d})$ : IL-13: $\mathrm{n}=3-4 ; \mathrm{p}=0.002 ; \mathrm{p}=0.018 ; \mathrm{p}=0.017)$. (e). BALF was retrieved and BAL cells were incubated with antibodies against CD3, CD45R, CCR3 and Gr-1 and subsequently analyzed by flow cytometry. CD $3^{-} \mathrm{CD} 45 \mathrm{R}^{-} \mathrm{CCR} 3^{-} \mathrm{Gr}-1^{+}$cells were counted as neutrophils ( $(\mathrm{b}) . \mathrm{n}=3-4 ; \mathrm{p}=0.039 ; \mathrm{p}=0.029 ; \mathrm{p}=0.036 ; \mathrm{p}=0.015)$. (f). Total lung cells from OVA and OVA + rIL-17A treated mice were incubated with antibodies against CD4, CD25 and Foxp3 and analyzed by flow cytometry $(\mathrm{n}=3-4 ; \mathrm{p}=0.001 ; \mathrm{p}=0.002)$. (g). Lung CD4 ${ }^{+} \mathrm{T}$ cells from OVA alone and OVA + rIL-17A treated mice were isolated and incubated for $24 \mathrm{~h}$ with $\alpha$-CD3 and $\alpha$-CD28. The supernatants were analyzed by ELISA for IL-9 $(\mathrm{n}=2-3 ; \mathrm{p}=0.0004 ; \mathrm{p}=0.016)$.

elevation of SOCS3 in the lung of Tyk-2 deficient mice. SOCS3 is thought to play an important role in determining $\mathrm{T}$ cell responses $^{34}$. The data presented in this manuscript are consistent with an elevation of SOCS3 in DCs which limits the tolerogenic effect of DCs thus inducing $\mathrm{T}$ effector cells ${ }^{20,35}$.

SOCS3 deficient DCs have been shown to give rise to more effective T regulatory cells. Thus SOCS3 induces the development of more effector T cells such as Th2 and Th9 in the absence of Tyk-2. By contrast, the T regulatory cells are inhibited in the presence of SOCS3 in DCs.

IL-10 was induced in lung $\mathrm{CD}^{+}{ }^{+} \mathrm{T}$ cell supernatants from Tyk$2^{(-1-)}$ mice after allergen challenge. IL-10 is a cytokine which is also produced by T regulatory cells, Th2, Th9 and Th17 cells.

Mast cells are an important cell type in the pathophysiology of allergic asthma. We then analyzed the presence of mast cell inducing cytokines IL-3 and IL-9 and found that they were elevated in Tyk-2 $2^{(-1-)}$ mice compared to wild type mice after allergen treatment. Consistently, we could also detect an increase in mast cells in the lungs of these mice. IL- 9 has been described to induce SOCS3 which in turn inhibits IL-9. However, considering that mast cells as well as $\mathrm{T}$ effector cells develop in the absence of Tyk-2, it is possible that SOCS3 cannot inhibit IL-9 in Tyk-2 $2^{(-/-)}$ mice. In fact, SOCS3 binds to Tyk-2 and JAK2/JAK1 downstream of IL-9 and other cytokines using the same receptor $\gamma$ chain $^{8,20,28}$. It could be already demonstrated that IL-21 is expressed in activated human $\mathrm{CD}^{+} \mathrm{T}$ cells but not in most other tissues. Furthermore, the expression of IL-21 is up-regulated in Th2 and Th17 subsets of $\mathrm{T}$ helper cells, as well as $\mathrm{T}$ follicular helper (Tfh) cells. In addition, IL-21 is expressed in NKT cells regulating the function of these cells. A study using mice with peanut allergies showed that systemic treatment with IL-21 effectively weaked the allergic response $^{36-39}$. In conclusion, the low levels of IL-21 in the BALF in asthma could be consistent with the decreased production of this cytokine by NKT cells thus favoring IgE development in allergy. By contrast, the increase of IL-21 in lung $\mathrm{CD} 4^{+} \mathrm{T}$ cell supernatants might reflect the expansion of the Thf and Th2 cells in asthma.

These Th17 cells however cannot be supported by IL-23 because it was found decreased especially in Tyk-2 $2^{(-l-)}$ asthmatic mice.

IL-17A has been described to play a role in inducing airway hyperresponsiveness ${ }^{40}$. Since Tyk- $2^{(-1-)}$ mice show a much more severe asthmatic phenotype but no elevated AHR compared to wild-type mice we applied this cytokine during allergen challenge. Wild-type mice showed increased neutrophils in the BALF compared to Tyk$2^{(-/-)}$mice after allergen challenge. Treatment with recombinant IL$17 \mathrm{~A}$ led to an increase in BAL neutrophils in both mouse strains compared to respective OVA treated mice. However, this effect was significantly stronger in wild type mice suggesting a reduced recruiting capacity in Tyk- $2^{(-1-)}$ mice which was not rescued by 
exogenous IL-17A. Moreover, IL-17A treatment led to a reduction in Th2 cytokine production in Tyk- $2^{(--)}$mice while the production was not altered in wild type mice. In accordance with the findings from Bettelli and co-workers we think that IL-17A is able to block Th2 cytokine production in a Tyk-2-dependent manner ${ }^{31}$. Also, IL$17 \mathrm{~A}$ led to a down-regulation of regulatory $\mathrm{T}$ cells in Tyk-2 $2^{(-/-)}$mice, while their number in the wild-type littermates remained unchanged. These data are consistent with an up-regulation of SOCS3 in the lung of Tyk- 2 deficient mice. IL- 9 was found unchanged in lung $\mathrm{CD} 4^{+} \mathrm{T}$ cells before and after in vivo rIL-17A treatment of Tyk-2 $2^{(-1-)}$ mice suggesting that IL-17A does not influence directly IL-9 production in T cells ${ }^{41}$.

Altogether, these results demonstrate a reduced survival fitness of the Th17 in the absence of Tyk-2 mediated by the up-regulation of SOCS3 that should be considered for a therapeutic setting in allergy as well as in autoimmune diseases and cancer.

\section{Methods}

All methods were carried out in accordance with the approved guidelines.

Mice. Tyk- $2^{(--)}$and wild-type mice on a Balb/c genetic background were used at the age of 6 to 8 weeks. All experiments were undertaken with the approved licenses (23177-07/G09-1-008, 23177-07/051-1V2 from ethical Review Board; Rheinland-Pfalz and 54-2532.1-2/10 from Bavaria). One to three independent experiments were performed, one representative experiment is shown.

OVA sensitization and challenge. Female Tyk-2 $2^{(-l)}$ and wild-type mice on a Balb/c background were maintained under specific pathogen-free conditions and received i.p. injections of $500 \mu \mathrm{g} / \mathrm{ml}$ ovalbumin (Calbiochem, Gibbstown, NJ) complexed with $10 \%$ alum (Sigma-Aldrich, Steinheim, Germany) on days 0 and 7 as previously described ${ }^{42,43}$. On days 18,19 and 20 the animals received ovalbumin in PBS via aerosol (10 $\mathrm{mg}$ ovalbumin/ml PBS in aerosol solution) for 30 minutes in a chamber connected to an aerosol generator (Föhr Medical Instruments, Seeheim, Germany). Twenty-four hours after the last aerosol, invasive whole-body plethysmography was performed to measure airway resistance and mice were sacrificed afterwards to isolate lung or spleen cells as previously described. For recombinant IL-17A treatment mice were anaesthetized 60 minutes before allergic challenge was performed and given $100 \mathrm{ng}$ (IL-17A) intranasally on days 18, 19 and 20.

Assessment of AHR and collection and analysis of bronchoalveolar lavage. To measure airway reactivity, we used whole-body plethysmography as previously described $^{43,44}$. Data are expressed as mean values of "airway resistance $[\mathrm{RI}] /$ baseline $\mathrm{RI"} \pm$ SEM. After plethysmography, bronchoalveolar lavage of the right lung was performed twice with $800 \mu \mathrm{L}$ saline each. BALF supernatants were frozen and subsequently analyzed by ELISA. The cell pellet was resuspended in PBS and counted (CASY@ TT, Roche Diagnostics, Mannheim, Germany) and subsequently used for cytospin analysis after staining with May-Grünwald-Giemsa solution (Carl Roth, Karlsruhe, Germany) or for Flow Cytometric Analysis (FACS).

Histology. Lungs were removed, fixed in 10\% formalin-PBS solution, dehydrated and embedded in paraffin. $5 \mu \mathrm{m}$ thick sections were stained with Masson-Goldner staining for quantification of collagen deposition ${ }^{45}$ or with Toluidine Blue for mast cell staining.

Isolation and analysis of lung and spleen $\mathrm{CD}^{+}{ }^{+} \mathrm{T}$ cells and cell culture. Lung $\mathrm{CD} 4$ $\mathrm{T}$ cells were positively sorted by magnetic bead isolation (MACS, Miltenyi Biotec, Bergisch-Gladbach) according to the manufacturer's protocol.

In some experiments lung and spleen $\mathrm{CD} 4^{+} \mathrm{T}$ cells were incubated with anti-CD3 $(2 \mu \mathrm{g} / \mathrm{ml})$, anti-CD28 $(2 \mu \mathrm{g} / \mathrm{ml})$. Antibodies were from hybridoma cell cultures. After 24 hours, or later as indicated, the supernatants were removed and analyzed by ELISA and RNA extracted from the cells.

Th17 skewing of spleen cells. Spleens were removed from naïve Tyk-2 and Balb/c mice and $\mathrm{CD} 4{ }^{+} \mathrm{CD} 62 \mathrm{~L}^{+}$were positively sorted by magnetic bead isolation (MACS, Miltenyi Biotec, Bergisch-Gladbach) according to the manufacturer's protocol. Cells were plated at a concentration of 1 Million per $\mathrm{ml}$ and were incubated with platebound anti-CD3 $(2 \mu \mathrm{g} / \mathrm{ml})$, anti-IL-4 $(10 \mu \mathrm{g} / \mathrm{ml})$, anti-IFN $\gamma(10 \mu \mathrm{g} / \mathrm{ml})$, TGF- $\beta$ $(3 \mathrm{ng} / \mathrm{ml})$ and anti-CD28 $(2 \mu \mathrm{g} / \mathrm{ml})$ antibodies. Additionally cells received $20 \mathrm{ng} / \mathrm{ml}$ recombinant IL-6 with or without $80 \mathrm{ng} / \mathrm{ml}$ of recombinant IL-21 or $50 \mathrm{ng} / \mathrm{ml}$ of recombinant IL-23. After three days IL-2 was added and on day 5 supernatants were frozen.

Flow cytometric analysis, intracellular staining and proliferation assay. Total lung cells were stained with antibodies for $30 \mathrm{~min}$ at $4^{\circ} \mathrm{C}$, washed in PBS, and then analyzed on a FACS-Calibur (BD Pharmingen, Heidelberg, Germany). The following FITC-, PE-, PerCP or APC-conjugated monoclonal antibodies were used for flow cytometry: CCR3, CD3, CD4 (L3T4), CD25, CD45R, Gr-1, Foxp3, IL-17A, ckit and FceRI. Antibodies were purchased from BD Pharmingen (BD Pharmingen,
Heidelberg, Germany), Miltenyi Biotec (Miltenyi Biotec, Bergisch-Gladbach) or eBioscience (eBioscience, Frankfurt, Germany).

For intracellular staining for Foxp3 cells were stained with anti-CD4 (L3T4; BD Pharmingen) and anti-CD25 (BD Pharmingen, Heidelberg, Germany) antibodies for $30 \mathrm{~min}$ at $4^{\circ} \mathrm{C}$. Afterwards, cells were fixed with fixation/permeabilization solution (eBioscience, Frankfurt, Germany) for $35 \mathrm{~min}$ at $4{ }^{\circ} \mathrm{C}$ and washed with permeabilization buffer (eBioscience, Frankfurt, Germany). Cells were then incubated with antibodies against Foxp3 (Miltenyi Biotec, Bergisch-Gladbach, Germany) for $30 \mathrm{~min}$ at $4^{\circ} \mathrm{C}$ in permeabilization buffer and washed once.

For intracellular staining of IL-17A, freshly isolated lung cells were incubated over night with anti-CD3 and anti-CD28 at $37^{\circ} \mathrm{C}$. Then they were stimulated with $1 \mathrm{ng} / \mathrm{ml}$ PMA (Sigma-Aldrich, Steinheim, Germany), $1 \mu$ M Ionomycin (Sigma-Aldrich, Steinheim, Germany), and GolgiStop (BD Pharmingen, Heidelberg, Germany) for $4 \mathrm{~h}$. After harvesting cells, the same protocol as for Foxp3 staining was used.

Furthermore, a proliferation assay with $\mathrm{CD}_{4}^{+}$lung cells was performed as previously described ${ }^{25}$.

ELISA. Mouse IL-3 (7.8-500 pg/ml), IL-4 (7.48-500 pg/ml), IL-5 (15.6-1000 pg/ $\mathrm{ml})$, IL-6 (15.6-1000 pg/ml), IgE (1.6-100 ng/ml), IgG $(31.3-2000 \mathrm{pg} / \mathrm{ml})$, were detected by using a specific sandwich ELISA (OptEIA; BD Pharmingen, Heidelberg, Germany). ELISA kits for mouse IL-1 $\beta(15.6-1000 \mathrm{pg} / \mathrm{ml})$, IL-13 (15.6-1000 pg/ml) IL-17A (15.6-1000 pg/ml), IL-17F (23.4-1500 pg/ml), IL$21(62.5-4000 \mathrm{pg} / \mathrm{ml}), \mathrm{IL}-23(39.1-2500 \mathrm{pg} / \mathrm{ml})$ and TGF- $\beta(15.6-1000 \mathrm{pg} / \mathrm{ml})$ were from DuoSet; R\&D, Wiesbaden, Germany. IL-9 (30-4000 pg/ml) was determined using a Ready!Set!Go! from eBioscience (Frankfurt, Germany)

qPCR. Lungs were removed and stored in peqGold RNA Pure (peqlab, Erlangen, Germany) at $-80^{\circ} \mathrm{C}$ until analysis. Tissue was homogenized in peqGold RNA Pure and used for RNA extraction according to the manufacturer's protocol. Cells were also lysed directly on the cell culture plate and taken for RNA extraction. Briefly, cells were treated with chloroform (Roth, Karlsruhe, Germany) and RNA was precipitated with isopropanol (Roth, Karlsruhe, Germany). RNA concentration in each sample was determined using a spectrophotometer (Nanodrop, peqlab, Erlangen, Germany) One $\mu \mathrm{g}$ of RNA was reverse-transcribed to cDNA using the RevertAid ${ }^{\mathrm{TM}}$ First Strand cDNA Synthesis Kit (Fermentas, St. Leon-Rot, Germany) according to the instructions. Twenty ng of cDNA was used in each reaction and added to $2 \times$ SsoFast ${ }^{\mathrm{TM}}$ EvaGreen ${ }^{\circledR}$ Supermix (BIO-RAD, Munich, Germany) and $200 \mathrm{nM}$ primer. Murine primers for $I L-9$ (fwd: $5^{\prime}$-CTG ATG ATT GTA CCA CAC CGT GC-3', rev: 5'-GCC TTT GCA TCT CTG TCT TCT GG-3'), Irf4 (fwd: $5^{\prime}$-ACG CTG CCC TCT TCA AGG CTT-3', rev: 5' -TGG CTC CTC TCG ACC AAT TCC-3'), IL-17A (fwd: 5'-TCC AGA AGG CCC TCA GAC TA, rev: 5' -AGC ATC TTC TCG ACC CTG AA3'), Pu. 1 (fwd: GCA TCT GGT GGG TGG ACA A, rev: TCT TGC CGT AGT TGC GCA G), Socs3 (fwd: GTT CCT GGA TCA GTA TGA TGC, rev: CGC TTG TCA AAG GTA TTG TCC), Stat5 (fwd: CGC TGG ACT CCA TGC TTC TC, rev: GAC GTG GGC TCC TTA CAC TGA) and as control Hprt (for: $5^{\prime}$-GCC CCA AAA TGG TTA AGG TT-3', rev: $5^{\prime}$-TTG CGC TCA TCT TAG GCT TT-3') were purchased from Eurofins-MWG-Operon, Ebersberg, Germany. qPCR was run on CFX-96 RealTime PCR Detection System (BIO-RAD, Munich, Germany), and analyzed with CFX Manager Software.

Statistical analysis. Differences were evaluated for significance $(* \mathrm{p} \leq 0.05 ; * * \mathrm{p} \leq$ $0.01, * * * \mathrm{p} \leq 0.001)$ with the Student-two-tailed t test for independent events by using statistical analysis (Excel, Microsoft, version 2003). Data are given as mean values \pm SEM.

1. Ghoreschi, K., Laurence, A. \& O'Shea, J. J. Janus kinases in immune cell signaling. Immunological reviews 228, 273-287 (2009).

2. Velazquez, L., Fellous, M., Stark, G. R. \& Pellegrini, S. A protein tyrosine kinase in the interferon alpha/beta signaling pathway. Cell 70, 313-322 (1992).

3. Watford, W. T. \& O'Shea, J. J. Human tyk2 kinase deficiency: another primary immunodeficiency syndrome. Immunity 25, 695-697 (2006).

4. Stahl, N. et al. Association and activation of Jak-Tyk kinases by CNTF-LIF-OSMIL-6 beta receptor components. Science 263, 92-95 (1994).

5. Shimoda, K. et al. Tyk2 plays a restricted role in IFN alpha signaling, although it is required for IL-12-mediated T cell function. Immunity 13, 561-571 (2000).

6. Karaghiosoff, M. et al. Partial impairment of cytokine responses in Tyk2-deficient mice. Immunity 13, 549-560 (2000).

7. Minegishi, Y. et al. Human tyrosine kinase 2 deficiency reveals its requisite roles in multiple cytokine signals involved in innate and acquired immunity. Immunity 25, 745-755 (2006).

8. Ubel, C., Mousset, S., Trufa, D., Sirbu, H. \& Finotto, S. Establishing the role of tyrosine kinase 2 in cancer. Oncoimmunology 2, e22840 (2013).

9. Eder, W., Ege, M. J. \& von Mutius, E. The asthma epidemic. N Engl J Med 355, 2226-2235 (2006).

10. Pearce, N. et al. Worldwide trends in the prevalence of asthma symptoms: phase III of the International Study of Asthma and Allergies in Childhood (ISAAC). Thorax 62, 758-766 (2007).

11. Schmitt, E., Van Brandwijk, R., Van Snick, J., Siebold, B. \& Rude, E. TCGF III/P40 is produced by naive murine $\mathrm{CD} 4+\mathrm{T}$ cells but is not a general $\mathrm{T}$ cell growth factor. Eur J Immunol 19, 2167-2170 (1989). 
12. Temann, U. A., Geba, G. P., Rankin, J. A. \& Flavell, R. A. Expression of interleukin 9 in the lungs of transgenic mice causes airway inflammation, mast cell hyperplasia, and bronchial hyperresponsiveness. J Exp Med 188, 1307-1320 (1998)

13. Staudt, V. et al. Interferon-regulatory factor 4 is essential for the developmental program of T helper 9 cells. Immunity 33, 192-202 (2010).

14. Dardalhon, V. et al. IL-4 inhibits TGF-beta-induced Foxp3 + T cells and, together with TGF-beta, generates IL-9+ IL-10+ Foxp3(-) effector T cells. Nat Immunol 9, 1347-1355 (2008).

15. Schnyder-Candrian, S. et al. Interleukin-17 is a negative regulator of established allergic asthma. J Exp Med 203, 2715-2725 (2006).

16. Barczyk, A., Pierzchala, W. \& Sozanska, E. Interleukin-17 in sputum correlates with airway hyperresponsiveness to methacholine. Respir Med 97, 726-733 (2003).

17. Wilson, R. H. et al. Allergic sensitization through the airway primes Th17dependent neutrophilia and airway hyperresponsiveness. Am J Respir Crit Care Med 180, 720-730 (2009).

18. Al-Ramli, W. et al. T(H)17-associated cytokines (IL-17A and IL-17F) in severe asthma. J Allergy Clin Immunol 123, 1185-1187 (2009).

19. Taube, C. \& Buhl, R. Does phenotyping asthma help to improve differential treatment? Dtsch Med Wochenschr 135, 468-473 (2010).

20. White, C. A. \& Nicola, N. A. SOCS3: An essential physiological inhibitor of signaling by interleukin-6 and G-CSF family cytokines. Jak-Stat 2, e25045 (2013).

21. Seto, Y. et al. Enhanced Th2 cell-mediated allergic inflammation in Tyk2-deficient mice. J Immunol 170, 1077-1083 (2003).

22. Huber, M. et al. IRF4 is essential for IL-21-mediated induction, amplification, and stabilization of the Th17 phenotype. Proc Natl Acad Sci U S A 105, 20846-20851 (2008).

23. Brustle, A. et al. The development of inflammatory $\mathrm{T}(\mathrm{H})-17$ cells requires interferon-regulatory factor 4. Nat Immunol 8, 958-966 (2007).

24. Chang, H. C. et al. The transcription factor PU.1 is required for the development of IL-9-producing T cells and allergic inflammation. Nat Immunol 11, 527-534 (2010).

25. Doganci, A. et al. The IL-6R alpha chain controls lung CD4+CD25+ Treg development and function during allergic airway inflammation in vivo. J Clin Invest 115, 313-325 (2005).

26. Fantini, M. C. et al. IL-21 regulates experimental colitis by modulating the balance between Treg and Th17 cells. Eur J Immunol 37, 3155-3163 (2007).

27. Schmitt, E. et al. IL-9 production of naive CD4+ T cells depends on IL-2, is synergistically enhanced by a combination of TGF-beta and IL-4, and is inhibited by IFN-gamma. J Immunol 153, 3989-3996 (1994).

28. Noelle, R. J. \& Nowak, E. C. Cellular sources and immune functions of interleukin9. Nat Rev Immunol 10, 683-687 (2010).

29. Lejeune, D., Demoulin, J. B. \& Renauld, J. C. Interleukin 9 induces expression of three cytokine signal inhibitors: cytokine-inducible $\mathrm{SH} 2$-containing protein, suppressor of cytokine signalling (SOCS)-2 and SOCS-3, but only SOCS-3 overexpression suppresses interleukin 9 signalling. Biochem J 353, 109-116 (2001).

30. Bacon, C. M. et al. Interleukin 12 (IL-12) induces tyrosine phosphorylation of JAK2 and TYK2: differential use of Janus family tyrosine kinases by IL-2 and IL12. J Exp Med 181, 399-404 (1995).

31. Bettelli, E. et al. Reciprocal developmental pathways for the generation of pathogenic effector TH17 and regulatory T cells. Nature 441, 235-238 (2006).

32. Berger, H. et al. SOCS3 transactivation by PPARgamma prevents IL-17-driven cancer growth. Cancer Res 73, 3578-3590 (2013).

33. Kim, H. Y., DeKruyff, R. H. \& Umetsu, D. T. The many paths to asthma: phenotype shaped by innate and adaptive immunity. Nat Immunol 11, 577-584 (2010).

34. Matsumura, Y. et al. Selective expansion of foxp3-positive regulatory T cells and immunosuppression by suppressors of cytokine signaling 3-deficient dendritic cells. J Immunol 179, 2170-2179 (2007).
35. Pillemer, B. B., Xu, H., Oriss, T. B., Qi, Z. \& Ray, A. Deficient SOCS3 expression in $\mathrm{CD} 4+\mathrm{CD} 25+$ FoxP3 + regulatory $\mathrm{T}$ cells and SOCS3-mediated suppression of Treg function. Eur J Immunol 37, 2082-2089 (2007).

36. Ozaki, K. et al. A critical role for IL-21 in regulating immunoglobulin production. Science 298, 1630-1634 (2002).

37. Hiromura, Y. et al. IL-21 administration into the nostril alleviates murine allergic rhinitis. J Immunol 179, 7157-7165 (2007).

38. Kishida, T. et al. IL-21 induces inhibitor of differentiation 2 and leads to complete abrogation of anaphylaxis in mice. J Immunol 179, 8554-8561 (2007).

39. Li, Y., Bleakley, M. \& Yee, C. IL-21 influences the frequency, phenotype, and affinity of the antigen-specific CD8 T cell response. J Immunol 175, 2261-2269 (2005).

40. Linden, A., Hoshino, H. \& Laan, M. Airway neutrophils and interleukin-17. Eur Respir J 15, 973-977 (2000)

41. Wilhelm, C., Turner, J. E., Van Snick, J. \& Stockinger, B. The many lives of IL-9: a question of survival. Nat Immunol 13, 637-641 (2012).

42. Finotto, S. et al. Treatment of allergic airway inflammation and hyperresponsiveness by antisense-induced local blockade of GATA-3 expression. J Exp Med 193, 1247-1260 (2001).

43. Finotto, S. et al. Development of spontaneous airway changes consistent with human asthma in mice lacking T-bet. Science 295, 336-338 (2002).

44. Finotto, S. et al. Asthmatic changes in mice lacking T-bet are mediated by IL-13 Int Immunol 17, 993-1007 (2005).

45. Doganci, A. et al. IL-2 receptor beta-chain signaling controls immunosuppressive $\mathrm{CD} 4+\mathrm{T}$ cells in the draining lymph nodes and lung during allergic airway inflammation in vivo. J Immunol 181, 1917-1926 (2008).

\section{Acknowledgments}

We thank D. Engelbrecht and A. Geiger for animal husbandry, and S. Trump, M. Mathews, M.Schubert, A. Mattil for their technical assistance. We thank S. Mousset for graphic improvement of the figures. This work was supported by the department of Molecular Pneumology in Erlangen. Initially CÜ's PhD was supported by a DFG and the Graduiertenkolleg GRK 1043 “Antigen-specific Immunotherapy” in Mainz and later by a DFG grant in Erlangen (Germany). Mice were originally provided to us by Mathias Müller (University of Veterinary Medicine, Vienna). A.G. is supported by the EU grant Predicta. We acknowledge support by Deutsche Forschungsgemeinschaft and

Friedrich-Alexander-Universität Erlangen-Nürnberg (FAU) within the funding programme Open Access Publishing.

\section{Author contributions}

C.Ü. and S.F. designed the experiments; C.Ü. and A.G. performed the experiments; R.J.R. and H.-A.L. performed histological analysis; C.Ü., A.G. and S.F. wrote the paper; and M.M., A.G. and S.F. edited the paper.

\section{Additional information}

Supplementary information accompanies this paper at http://www.nature.com/ scientificreports

Competing financial interests: The authors declare no competing financial interests.

How to cite this article: Übel, C. et al. Role of Tyk-2 in Th9 and Th17 cells in allergic asthma. Sci. Rep. 4, 5865; DOI:10.1038/srep05865 (2014).

This work is licensed under a Creative Commons Attribution-NonCommercialNoDerivs 4.0 International License. The images or other third party material in this article are included in the article's Creative Commons license, unless indicated otherwise in the credit line; if the material is not included under the Creative Commons license, users will need to obtain permission from the license holder in order to reproduce the material. To view a copy of this license, visit http:// creativecommons.org/licenses/by-nc-nd/4.0/ 